\title{
Effectiveness of Long-Acting Injectable Antipsychotics in Schizophrenia: A Literature Review and Bayesian Meta-Analysis Informing Economic Considerations
}

\author{
Orietta Zaniolo ${ }^{1}$, Gianni Ghetti ${ }^{1}$, Massimiliano Povero ${ }^{1}$, Lorenzo Pradelli ${ }^{1}$
}

${ }^{1}$ AdRes - Health Economics \& Outcome Research, Turin

\begin{abstract}
BACKGROUND: Although the use of long-acting injectable antipsychotics (LAIs) is considered an important option in the management of schizophrenia two recent meta-analysis, which aimed to compare LAIs vs oral antipsychotics (OAPs) in terms of relapse rate, showed discordant results.

AIM: To investigate factors affecting the efficacy of antipsychotics in terms of relapse prevention in the real-world and to estimate the management cost of an episode of relapse.

METHODS: We conducted a literature search using MEDLINE/PubMed with the aim to extract efficacy, effectiveness and adherence data of LAIs and OAPs. The primary outcome was the relative risk (RR) of relapse between two strategies. The extracted RR were included in a series of Bayesian statistical models based on the starting hypotheses. The RR rates obtained from the meta-analysis have been used as input for an economic evaluation of the total costs associated with the management of the patient with schizophrenia from the Italian NHS perspective.

RESULTS: The literature search identified 34 studies which met the inclusion criteria and were analyzed. According to the model that best explains the data, in the real-world setting the effectiveness with LAIs is greater than with OAPs, with a more pronounced effect for SGAs than for FGAs. Taking into account generation, route and frequency of administration, the RR decreased with lower administration frequency, with SGA LAI administered once every 90 days which is associated with the greatest reduction in the risk of relapse $(-85 \%)$. When the results of the meta-analysis are used to feed an economic evaluation the results show that the SGA administered every 90 days is the strategy with the least expected cumulative cost both at $1(€ 3,509)$ and 5 years $(€ 19,690)$.

CONCLUSION: SGA LAIs administered every 90 days seems to be the best option for the treatment of patient with schizophrenia from both the clinical and economic perspectives.
\end{abstract}

\section{Keywords}

Long-acting injectable antipsychotics; Schizophrenia; Relapse; Italy

\section{INTRODUCTION}

Despite there have been significant pharmacological progresses and improvements in individual and community assistance, schizophrenia remains a disabling, chronic disease with alternating periods of remission and relapse. Since each subsequent relapse exacerbates the clinical deterioration of the patient, with consequent worsening of symptoms, progressive cognitive impairment, functioning deterioration, and reduced quality of life, one of the major goals of schizophrenia treatment is to prevent or delay relapse [1-5].

Long-acting injectable antipsychotics (LAIs) were introduced in clinical practice in the 1960s with the aim of overcoming the limits associated with oral antipsychotics (OAPs) in terms of treatment adherence and pharmacokinetics profile [2-7].

Although the use of LAIs is considered an important option, in particular for patients with adherence problems $[2,3,5,8]$, two recent meta-analyzes $[9,10]$, which aimed to compare LAIs

Corresponding author Lorenzo Pradelli I.pradelli@adreshe.com 
vs OAPs in terms of relapse rate, showed discordant results between randomized clinical trials (RCTs) and mirror-image studies.

The first meta-analysis [10] included only RCTs lasting more than 6 months, which compared LAIs and OAPs. The primary outcome was the relapse rate at the longest study time point; secondary outcomes included the relapse rate at specific time points $(3,6,12,18$, and 24 months), all-cause discontinuation, discontinuation due to adverse events, drug inefficacy, hospitalization and non-adherence. A total of 21 RCTs were included in the analysis and the results showed that, when pooled together, LAIs did not reduce relapse compared with OAPs. In particular, pooled LAIs only showed trend-level superiority over OAPs in preventing hospitalization $(\mathrm{RR}=0.88 ; 95 \% \mathrm{CI}$ : $0.78-1.02 ; \mathrm{p}=0.09)$ with a gradient related to the frequency of administration (longer intervals of administration were associated with a greater reduction of relapse rate) and pharmacological class (relapse rate with SGA was lower than with FGA).

Since the patients enrolled in RCTs are generally different from those in real-world studies in terms of adherence rate and illness severity, the second meta-analysis conducted by Kishimoto et al. [9] was based on 25 mirror-image studies, which better reflect the real-world setting. The study included mirror-image studies that compared period $\geq 6$ months with OAPs and $\geq 6$ months with LAIs in adults with schizophrenia and that reported information about hospitalization or relapse-related data. The primary outcomes were hospitalization risk and the total number of hospitalizations, while secondary outcomes included total hospitalization days and length of stay. The results of this meta-analysis show a statistically significant superiority of LAIs over OAPs in preventing hospitalization $(\mathrm{RR}=0.43,95 \% \mathrm{CI}$ : $0.35-0.53$; $\mathrm{p}<0.001)$ and decreasing the number of hospitalizations $(\mathrm{RR}=0.38 ; 95 \% \mathrm{CI}: 0.28-0.51 ; \mathrm{p}$ $<0.001)$.

In the light of these results we conducted a comprehensive literature review and meta-analyzed the retrieved data by use of a Bayesian hierarchical model, with the aim to investigate factors affecting the efficacy of antipsychotics in terms of relapse prevention in the real-world (effectiveness). The results of the meta-analysis have been used as input for an economic evaluation of the total costs associated with the management of the patient with schizophrenia from the Italian National Health System (NHS) perspective. Mean cumulative total cost per patient at 1 and 5 years, was calculated by antipsychotic treatment (first or second generation and administration frequency) and cost items (antipsychotic treatment and relapse management).

Methods and input data have been reviewed and approved by an Italian expert board (see Acknowledgements).

\section{METHODS}

Starting from the assumption that the antipsychotics effectiveness is a function of both their pharmacological and pharmacodynamics characteristics, on one side, and their use in real-world setting, on the other, a meta-analysis has been performed to test the following hypotheses:

1. In a real-world setting LAIs are associated with better adherence compared to OAPs;

2. In an experimental setting (RCT) a LAI and the same OAP have similar efficacy and adherence while in the real-world a net increase in the efficacy of LAI can be noted;

3. This phenomenon has a gradient and it becomes more evident when the administration is less frequent.

\section{Literature Search and Inclusion Criteria}

We conducted a literature search using MEDLINE/PubMed (last access May 18, 2017) with the aim to extract efficacy, effectiveness and adherence data of LAIs and OAPs.

The search strings (one for the search of efficacy/effectiveness data and one for the search of adherence data) have been designed on the basis of the PICOS schema (Table I), as recommended by the PRISMA guidelines [11].

Two independent investigators conducted the literature search; the revision and the selection of the studies were performed on the basis of title/abstract and then of the full-text. The electronic search through MEDLINE was supplemented by manual check of reference lists of included studies. Any disagreements were resolved by discussion or by the intervention of a third investigator. 


\begin{tabular}{|c|c|c|}
\hline PICOS component & Inclusion criteria & Exclusion criteria \\
\hline Participants & Adults with schizophrenia & $\begin{array}{l}\text { - Other mental disorder } \\
\text { - Acute phase } \\
\text { - Drug resistance } \\
\text { - Observational cohort studies }<50 \text { patients }\end{array}$ \\
\hline Intervention & $\begin{array}{l}\text { Oral or long-acting injectable monotherapy with } \\
\text { risperidone, paliperidone, aripiprazole, olanzapine, } \\
\text { haloperidol, fluphenazine, zuclopentixol }\end{array}$ & Any other treatment \\
\hline Comparators & $\begin{array}{l}\text { All (head to head, placebo, other formulation, other } \\
\text { or none) }\end{array}$ & - \\
\hline Outcome & $\begin{array}{l}\text { - Primary: relapse rate } \\
\text { - Secondary: treatment adherence }\end{array}$ & Absence of adherence or relapse outcome \\
\hline Study design & $\begin{array}{l}\text { - Efficacy: interventional studies (RCT, nRCT, } \\
\text { Uncontrolled Clinical Trial - UCT) } \\
\text { - Effectiveness: observational studies (cohort } \\
\text { longitudinal retrospective or prospective studies) } \\
\text { - Adherence: observational studies (cohort } \\
\text { longitudinal retrospective or prospective studies) }\end{array}$ & $\begin{array}{l}\text { - Review/meta-analyses } \\
\text { - Case-report/case series } \\
\text { - Preclinical studies }\end{array}$ \\
\hline Other & & $\begin{array}{l}\text { - Out of objective (scope): evaluation of the } \\
\text { effect of discontinuation therapy, switch, on-top/ } \\
\text { augmentation strategies; methodological and } \\
\text { pharmacokinetics studies } \\
\text { - Post-hoc or subgroup analyzes } \\
\text { - Unavailability of full-text }\end{array}$ \\
\hline
\end{tabular}

Table I. Inclusion and exclusion criteria

\section{Data Extraction and Data Analysis}

The primary outcome was the relative risk (RR) of relapse between two strategies. Therefore, we selected all the studies that compared two strategies differing in terms of active ingredient and/or administration route and/or inter-administration interval and extracted the adjusted relative risk (RR) from the text. When the relative risk was not reported, we estimated it from reported data as the ratio between absolute rates.

For RCTs we relied on the efficiency of randomization in minimizing the risk of bias, and took no further action, while for observational studies, this was done only in case of cohorts matched on risk factors for relapse, or statistically equivalent in terms of baseline characteristics. This implies that any observational study on mismatched cohorts did not contribute to the estimation of relative treatment effects.

The extracted relative risks were included in a series of Bayesian statistical models based on the starting hypotheses. In order to identify the hypothesis that best suited the data, three model sets based on alternative assumptions on the influence of administration were tested: route only, administration frequency only, or both.

For the effect of administration frequency on risk of relapse, proportional (RR depends on the ratio of frequencies) and additive (RR depends on the difference of frequencies) specifications were evaluated.

Finally, all model versions were evaluated with and without considering the generation of the AP (FGA vs. SGA).

For the relative effectiveness and economic outcome predictions, inference was based on the best model. This was identified by means of the Bayesian Information Criterion (BIC), which allows selecting the best model basing on goodness-of-fit and parsimony, with lower values indicating better performance.

The secondary outcome was the adherence, but the qualitative analysis of adherence data revealed extremely high heterogeneity in the measurement methods, in the outcomes and in the elaborations, in addition to poor reliability of the data for oral drugs. All these factors were judged to have a too high potential for bias to obtain a reliable result. For this reason adherence data were excluded from the quantitative analysis.

\section{Economic Evaluation}

The relative relapse rates obtained from the meta-analysis have been used to feed an economic evaluation of the total costs associated with the antipsychotic treatment over a time horizon of 1 and 5 years. 


\begin{tabular}{lccccc}
\hline & \multirow{2}{*}{ OAPs $(\boldsymbol{\epsilon})$} & \multicolumn{4}{c}{ LAls $(\boldsymbol{\epsilon})$} \\
\cline { 3 - 6 } & & 2-weekly & 3-weekly & Monthly & 3-Monthly \\
\hline FGA & 7.9 & - & 14.8 & 10.5 & - \\
SGA & 30.2 & 269.6 & - & 287.3 & 287.3 \\
\hline
\end{tabular}

Table II. Weighted average ex-factory prices

FGA OAP = haloperidol; SGA OAP = paliperidone, risperidone, olanzapine, aripiprazole; SGA 2-weekly = olanzapine, risperidone; FGA 3-weekly = fluphenazine; FGA monthly = haloperidol: SGA monthly = paliperidone, olanzapine, aripiprazole; SGA 3-monthly = assumed equal to SGA monthly

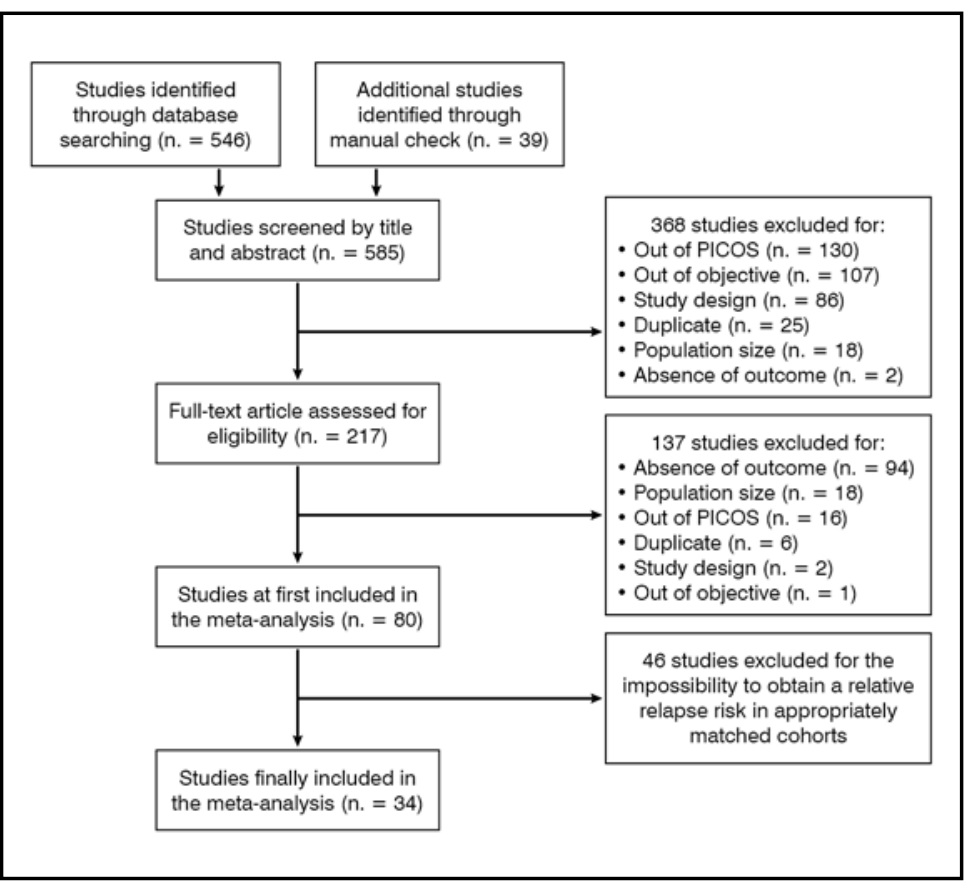

Figure 1. Flowchart of literature search
Since the analysis was performed from the Italian NHS perspective, only direct costs were considered. Drug acquisition costs were calculated taking into account the treatment mix reported by IQVIA for Italy in 2017 [12], their maximum acquisition cost for the NHS, the adherence rate and the time horizon.

Weighted average ex-factory prices for each category are reported in Table II. They have been estimated starting from ex-factory price for drugs in class $\mathrm{H}$ or $\mathrm{A}$ included in the PHT list [13] and retail price for drugs in class A non-included in the PHT list [13], after weighting the contribution of the different dose levels to the total sales of a single brand, and then weighing brands belonging to the same categories by their respective patient shares, as reported by sales data in 2017 [12].

The adherence rate was estimated (for costing purposes only) at $50 \%$ for OAPs, which is an average from the literature data. Applying the odds ratios estimated by Pillon et al. [14], the adherence rate for first generation $(71 \%)$ and second generation $(82 \%)$ LAIs was calculated.

The relapse management cost was calculated from the relapse rate by class and administration frequency obtained from the meta-analysis and the cost of managing an episode of relapse.

According to Expert opinion the cost of an episode of relapse was not only derived from the Diagnosis Related Group (DRG) tariff, which does not encompass the entire relapse management pathway, but it was calculated taking into account both hospitalization and the subsequent stay in residential facilities. In order to better represent the Italian context, the mean cost between Lazio, Lombardy, and Tuscany was used in the economic evaluation. The cost considered by the experts comprises the hospitalization for the acute phase for 10-15 days (proxied with the regional tariffs) and the following rehabilitation in a dedicated institution for a mean of 30 days: the resulting mean cost per relapse is $€ 10,500$.

In the 5 -year scenario every relapse increases the subsequent relapse rate by $20 \%[15,16]$.

\section{RESULTS}

\section{Search and Study Characteristics}

The literature search identified 546 studies, plus 39 studies added through manual check, for a total of 585 studies. Of these, 368 studies were excluded after the screening by title and abstract and 217 were fully inspected. Finally, 34 studies (20 RCTs) met the inclusion criteria and were analyzed (Figure 1). The details of the studies included are presented in Table III $[17-50]$.

\begin{tabular}{lcccc}
\hline \multicolumn{1}{c}{ Reference } & \multicolumn{1}{c}{ Comparators } & Patients (n.) & $\begin{array}{c}\text { Relative efficacy/ } \\
\text { effectiveness }\end{array}$ & Data extracted \\
\hline $\begin{array}{l}\text { Observational studies [17-30] } \\
\text { Baser, 2015 }\end{array}$ & PAL 30 vs. SGA OAPs & 335 vs. 335 & 0.623 & $\begin{array}{l}\text { Ratio between absolute rates in propensity } \\
\text { score matching } \\
\text { Ritter, } 2013\end{array}$ \\
RIS 14 vs. ARI oral & 1095 vs. 601 & 0.640 & $\begin{array}{l}\text { Ratio between absolute rates in propensity } \\
\text { score matching }\end{array}$
\end{tabular}


$>$ Table continued

\begin{tabular}{|c|c|c|c|c|}
\hline Reference & Comparators & Patients (n.) & $\begin{array}{l}\text { Relative efficacy/ } \\
\text { effectiveness }\end{array}$ & Data extracted \\
\hline Bitter, 2013 & RIS 14 vs. OLA oral & 1095 vs. 1633 & 0.767 & $\begin{array}{l}\text { Ratio between absolute rates in propensity } \\
\text { score matching }\end{array}$ \\
\hline Bitter, 2013 & RIS 14 vs. RIS oral & 1095 vs. 2480 & 0.387 & $\begin{array}{l}\text { Ratio between absolute rates in propensity } \\
\text { score matching }\end{array}$ \\
\hline $\begin{array}{l}\text { Grimaldi-Bensouda, } \\
2012\end{array}$ & RIS 14 vs. OAPs & 400 vs. 784 & 0.490 & Adjusted RR from text \\
\hline Guo, 2011 & OLA oral vs. ARI oral & 149 vs. 132 & 0.947 & Ratio between absolute rates \\
\hline Joshi, 2016 & PAL 30 vs. RIS 14 & 499 vs. 499 & 0.720 & Adjusted OR from text \\
\hline Lafeuille, 2015 & PAL 30 vs. OAPs & 374 vs. 32475 & 0.750 & HR from text \\
\hline Marcus, 2015 & FLU $14-42$ vs. OAPs & 45 vs. 3428 & 0.870 & Adjusted OR from text \\
\hline Marcus, 2015 & ALO 28 vs. OAPs & 112 vs. 3428 & 0.910 & Adjusted OR from text \\
\hline Marcus, 2015 & RIS 14 vs. OAPs & 81 vs. 3428 & 0.670 & Adjusted OR from text \\
\hline Marcus, 2015 & PAL 30 vs. OAPs & 102 vs. 3428 & 0.530 & Adjusted OR from text \\
\hline Morrato, 2015 & PAL 30 vs. SGA OAPs & 201 vs. 595 & 0.860 & Adjusted OR from text \\
\hline Ren, 2011 & RIS 14 vs. OAPs & 924 & 0.743 & Ratio between absolute rates \\
\hline Schreiner, 2014 & RIS 14 vs. SGA OAPs & 426 vs. 490 & 0.654 & Ratio between absolute rates \\
\hline Tiihonen, 2006 & OLA oral vs. ALO oral & 822 vs. 107 & 0.540 & Adjusted RR from text \\
\hline Tiihonen, 2006 & RIS oral vs. ALO oral & 651 vs. 107 & 0.890 & Adjusted RR from text \\
\hline Tiihonen, 2011 & RIS 14 vs. RIS oral & 51 vs. 411 & 0.570 & Adjusted HR from text \\
\hline Tiihonen, 2011 & ZUC 14 vs. ZUC oral & 30 vs. 6 & 0.490 & Adjusted HR from text \\
\hline Tiihonen, 2011 & ALO 28 vs. ALO oral & 6 vs. 9 & 0.120 & Adjusted HR from text \\
\hline Tiihonen, 2017 & RIS 14 vs. RIS oral & 3021 vs. 7016 & 0.859 & $\begin{array}{l}\text { Ratio between adjusted HR vs. no } \\
\text { treatment from text }\end{array}$ \\
\hline Tiihonen, 2017 & ZUC 14 vs. ZUC oral & 4083 vs. 3425 & 0.791 & $\begin{array}{l}\text { Ratio between adjusted HR vs. no } \\
\text { treatment from text }\end{array}$ \\
\hline Tiihonen, 2017 & OLA 14 vs. OLA oral & 400 vs. 1173 & 0.921 & $\begin{array}{l}\text { Ratio between adjusted HR vs. no } \\
\text { treatment from text }\end{array}$ \\
\hline Tiihonen, 2017 & ALO 28 vs. ALO oral & 1632 vs. 3348 & 0.790 & $\begin{array}{l}\text { Ratio between adjusted HR vs. no } \\
\text { treatment from text }\end{array}$ \\
\hline Voss, 2015 & PAL 30 vs. OAPs & 109 vs. 109 & 0.540 & HR from text \\
\hline \multicolumn{5}{|l|}{ RCT [31-50] } \\
\hline Alphs, 2015 & PAL 30 vs. OAPs & 226 vs. 218 & 0.681 & Ratio between absolute rates \\
\hline Buckley, 2014 & RIS 14 vs. OAPs & 146 vs. 150 & 1.285 & Ratio between absolute rates \\
\hline Carpenter, 1999 & FLU 14 vs. FLU 42 & 25 vs. 25 & 0.763 & Ratio between absolute rates \\
\hline Csernansky, 2002 & ALO oral vs. RIS oral & 188 vs. 177 & 1.930 & RR from text \\
\hline Detke, 2014 & OLA 28 vs. OLA oral & 264 vs. 260 & 1.086 & Ratio between absolute rates \\
\hline Fleischhacker, 2014 & ARI 28 vs. ARI oral & 265 vs. 266 & 0.985 & Ratio between absolute rates \\
\hline Glick, 2002 & OLA oral vs. ALO oral & 541 vs. 158 & 0.828 & Ratio between absolute rates \\
\hline Hogarty, 1979 & FLU 14 vs. FLU oral & 27 vs. 25 & 0.862 & Ratio between absolute rates \\
\hline Ishigooka, 2015 & ARI 28 vs. ARI oral & 228 vs. 227 & 0.920 & Ratio between absolute rates \\
\hline Kane, 2009 & OLA oral vs. ARI oral & 281 vs. 285 & 0.985 & Ratio between absolute rates \\
\hline Kane, 2010 & OLA 14 vs. OLA oral & 281 vs. 322 & 1.500 & Adjusted HR from text \\
\hline Kane, 2010 & OLA 28 vs. OLA oral & 318 vs. 322 & 1.400 & Adjusted HR from text \\
\hline Kane, 2010 & OLA 14 vs. OLA 28 & 281 vs. 318 & 1.000 & Adjusted HR from text \\
\hline Keks, 2007 & RIS 14 vs. OLA oral & 247 vs. 300 & 1.170 & Ratio between absolute rates \\
\hline Kim, 2008 & RIS 14 vs. RIS oral & 22 vs. 28 & 0.307 & Ratio between absolute rates \\
\hline Lieberman, 2005 & OLA oral vs. RIS oral & 330 vs. 333 & 0.575 & Ratio between absolute rates \\
\hline Malla, 2016 & RIS 14 vs. OAPs & 42 vs. 35 & 1.894 & Ratio between absolute rates \\
\hline McEvoy, 2014 & PAL 30 vs. ALO 28 & 145 vs. 145 & 1.294 & Ratio between absolute rates \\
\hline Rosenheck, 2011 & RIS 14 vs. OAPs & 187 vs. 182 & 0.870 & Adjusted HR from text \\
\hline Savitz, 2016 & PAL 90 vs. PAL 30 & 483 vs. 512 & 0.870 & HR from text \\
\hline Schooler, 1980 & FLU 21 vs. FLU oral & 107 vs. 107 & 0.668 & Ratio between absolute rates \\
\hline Schooler, 2005 & RIS oral vs. ALO oral & 197 vs. 203 & 0.864 & Ratio between absolute rates \\
\hline
\end{tabular}

Table III. Details of the studies included in the meta-analysis

$\mathrm{ALO}=$ haloperidol; $\mathrm{ARI}=$ aripiprazole; $\mathrm{FLU}=$ fluphenazine; OAP = oral antipsychotics; OLA = olanzapine;

$\mathrm{PAL}=$ paliperidone; $\mathrm{RIS}=$ risperidone; $\mathrm{SGA}=$ second generation antipsychotics; $\mathrm{ZUC}=$ zuclopentixol 


\begin{tabular}{lcccc}
\hline \multicolumn{1}{c}{ Treatment effect } & FGA: LAls vs. OAPs & SGA: LAl vs. OAPs & SGA vs. FGA & +7 days $^{1}$ \\
\hline RR $[95 \% \mathrm{Cl}]$ & $0.80[0.69-0.93]$ & $0.53[0.48-0.58]$ & $0.79[0.58-1.09]$ & $0.90[0.80-1.00]$ \\
Credibility $\left.^{2} \%\right)$ & 99.8 & 100 & 93.4 & 97.2 \\
\hline
\end{tabular}

Table IV. Best model results (real-world)

${ }^{1}$ Each additional 7 days of inter-dose interval

${ }^{2}$ Posterior probability of superiority, measured as percentage of iterations with $\mathrm{RR}<1$

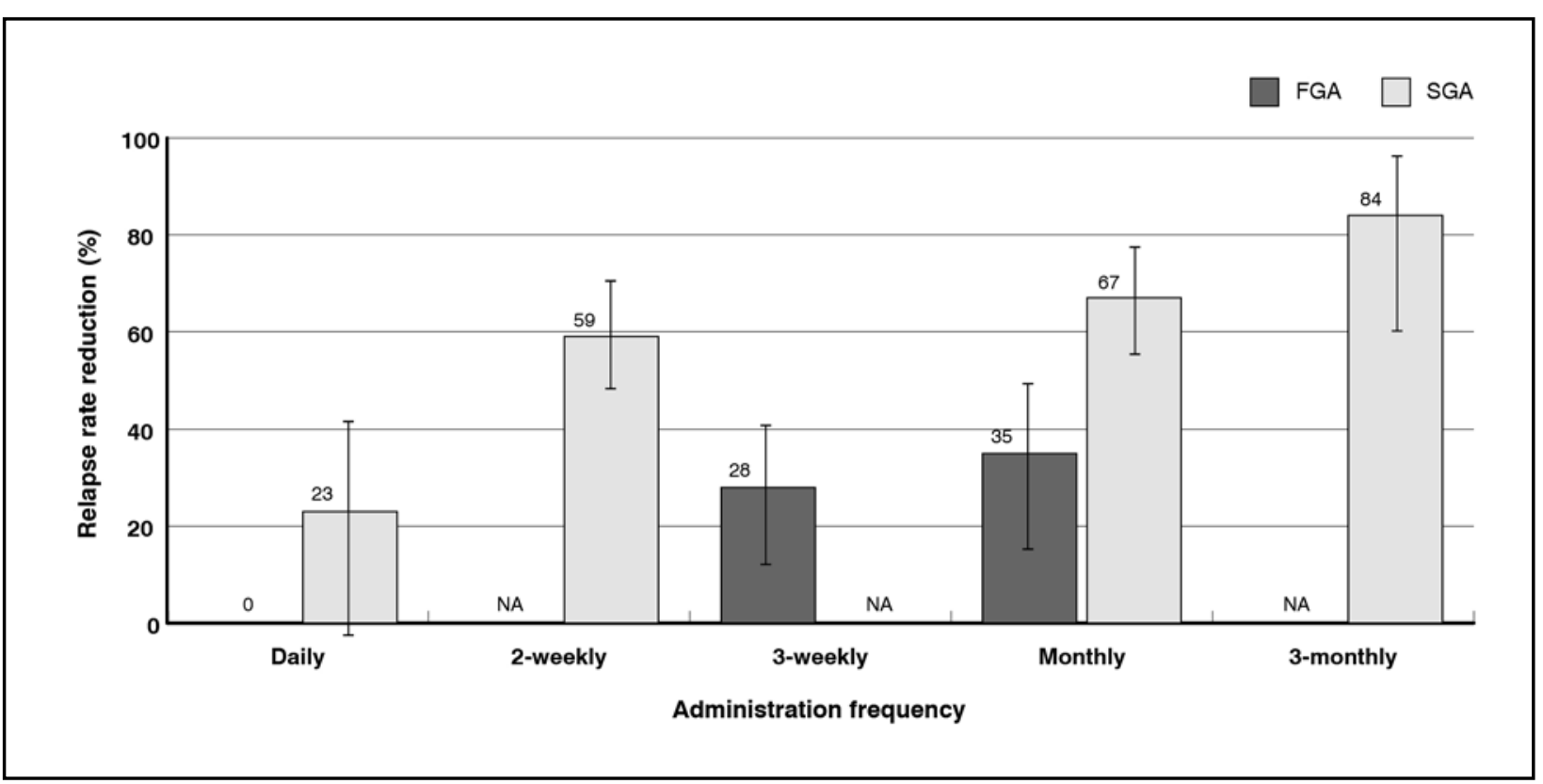

Figure 2. Relapse rate reduction vs oral FGA according to class and administration frequency

- Common results of all tested models indicate that:

- In real-world setting, the effectiveness is greater with LAIs than with orals- this effect is more pronounced for SGAs than for FGAs, while the route has no statistically significant effect under experimental conditions;

- In real-world settings the effectiveness significantly increases with decreasing administration frequency;

There are high probabilities (80-95\% in the best fitting models) that the intrinsic efficacy of SGAs is greater than that of FGAs.

The model best explaining the data was the one that comprises both the effect of route and frequency of administration (additive effect) and that considers a class effect (FGAs vs. SGAs) for both intrinsic efficacy and administration route effect (Table IV).

- According to this model:

- In the real world setting, a LAI reduces the risk of relapse, compared to the same AP given by the oral route, by $20 \%(\mathrm{RR}=0.8)$ if it belongs to the first generation, and by almost $50 \%(\mathrm{RR}=0.53)$ if a SGA;

- In the real world setting, the risk of relapse is reduced by $10 \%(\mathrm{RR}=0.9)$ for each additional week of inter-dose interval;

Second generation agents reduce the risk of relapse by almost $20 \%(R R=0.79)$ when compared to FGAs of equivalent route and frequency of administration.

Figure 2 shows the relative risks (vs. FG OAP, taken as reference) for all considered combinations of generation, route, and frequency of administration inferred by the model. As can be seen, relapse rate decreased with lower administration frequency, and the greatest reduction in the risk of relapse is expected with the use of a SGA LAI administered once every 90 days, associated with an estimated RR of $16 \%$, i.e. a reduction of $84 \%$ in the frequency of relapse, compared to the use of an oral, first generation, antipsychotic agent.

Credibility of results (i.e. posterior probability of superiority, measured as percentage of iterations with RR $<1$ - data not shown) resulted close to certainty (98-100\%) for the comparison of any LAI vs. any OAP, while there is substantial uncertainty in the comparison of oral SGAs versus first generation LAIs. 


\begin{tabular}{lcc|cc}
\hline \multirow{2}{*}{$\begin{array}{c}\text { Administration } \\
\text { frequency }\end{array}$} & \multicolumn{4}{c}{ Total cost per patient (€) } \\
\cline { 2 - 5 } & \multicolumn{2}{c}{$\mathbf{1}$ year } & FGA & SGA \\
\hline Daily & $6,086[4,112-8,472]$ & $4,753[3,425-6,332]$ & $45,180[30,480-62,950]$ & $34,930[25,060-46,670]$ \\
2-weekly & NA & $5,085[4,285-6,064]$ & NA & $31,370[25,590-38,570]$ \\
3-weekly & $4,493[2,793-6,697]$ & NA & $33130[20460-49520]$ & NA \\
Monthly & $4,022[2,380-6,196]$ & $4,786[4,085-5,643]$ & $29710[17480-45870]$ & $28,720[23,670-34,930]$ \\
3-monthly & NA & $3,795[3,045-5,275]$ & NA & $21,270[15,940-32,350]$ \\
\hline
\end{tabular}

Table V. Mean [ $95 \% \mathrm{Crl}$ cumulative total cost per patient at 1 and 5 years, by antipsychotic treatment

\begin{tabular}{|c|c|c|c|c|}
\hline \multirow{3}{*}{$\begin{array}{l}\text { Administration } \\
\text { frequency }\end{array}$} & \multicolumn{4}{|c|}{ Probability SGA 90-day less costly (mean delta) vs. } \\
\hline & FGA & SGA & FGA & SGA \\
\hline & \multicolumn{2}{|c|}{ After 1 year } & \multicolumn{2}{|c|}{ After 5 years } \\
\hline Daily & $98 \%(2,291 €)$ & $87 \%(958 €)$ & $100 \%(23,910 €)$ & $97 \%(13,660 €)$ \\
\hline 2-weekly & & $96 \%(1,290 €)$ & & $96 \%(10,100 €)$ \\
\hline 3-weekly & $77 \%(698 €)$ & & $97 \%(11,860 €)$ & \\
\hline Monthly & $58 \%(227 €)$ & 97\% (991€) & $93 \%(8,440 €)$ & $97 \%(7,450 €)$ \\
\hline
\end{tabular}

Table VI. Probability that the cumulative total cost per patient of alternative strategies is higher than SGA 90-day at 1 and 5 years, and their mean cost increase

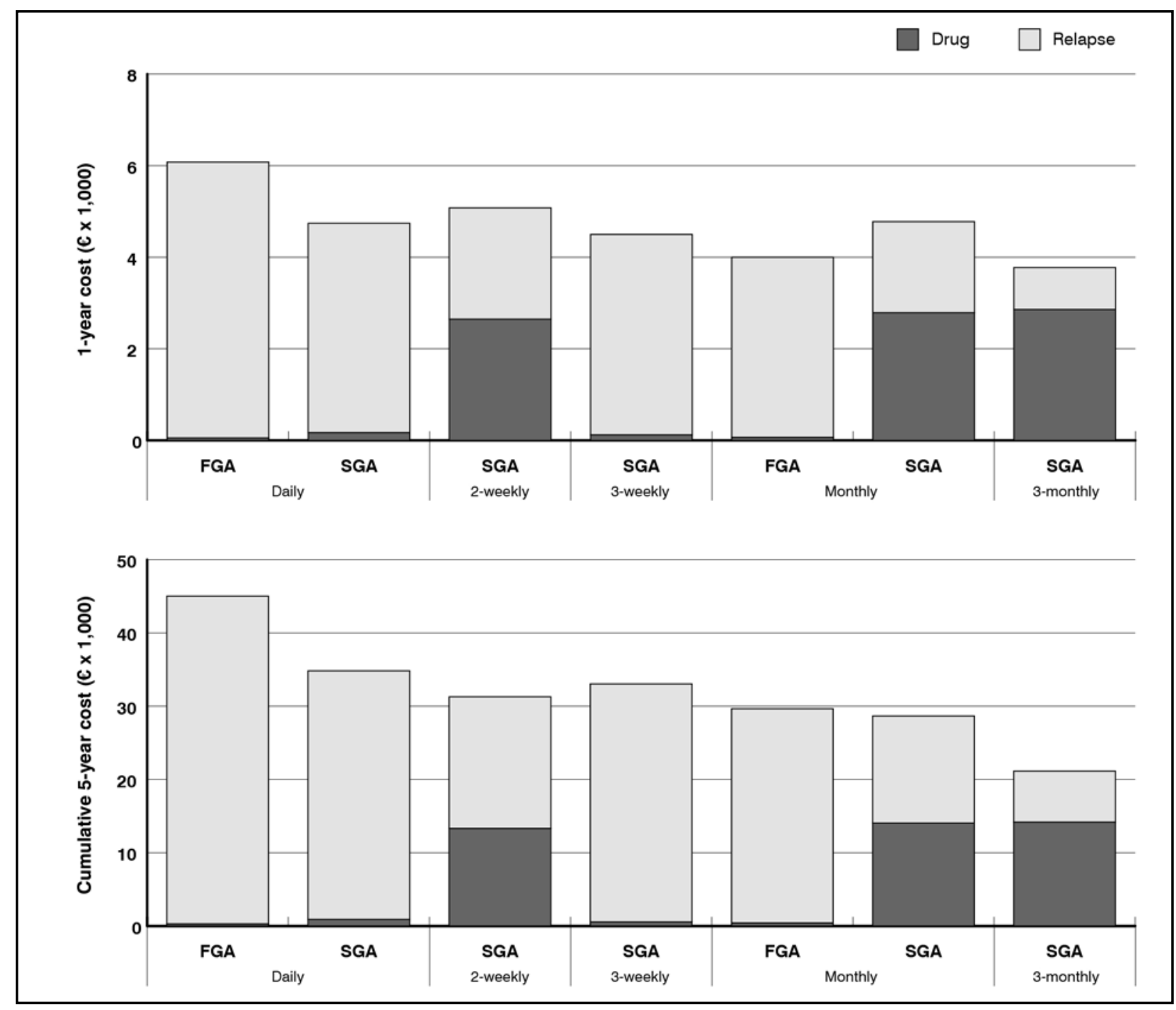

Figure 3. Mean cumulative total cost per patient at 1 and 5 years, by antipsychotic treatment and cost items 


\section{Economic Evaluation}

The average $(95 \% \mathrm{CrI})$ cumulative 1 year and 5 year cost for the management of a patient with schizophrenia estimated by the model for the available strategies are shown in Table V.

The data indicate that the strategy with the least expected cumulative cost is SGA administered every three months, already at one year, and more so in the medium term ( 5 years), with 91\% (data not shown) chances of being the least costly strategy (Table VI).

Observing the contribution of the single cost items to the total (Figure 3), it can be seen how the component related to the drug acquisition becomes more prevalent moving from the least to the most effective treatments, and how this trend becomes more evident with longer time horizons.

\section{DISCUSSION}

Long-acting injectable antipsychotics (LAIs) were introduced in the treatment of schizophrenia with the aim of improving treatment adherence and pharmacokinetics profile associated with OAPs.

Our meta-analysis, which aimed to investigate factors affecting the efficacy of antipsychotics in terms of relapse prevention in the real-world (effectiveness), shows that in the realworld setting the effectiveness with LAIs is greater than with OAPs, with a more pronounced effect for SGAs than for FGAs. In particular, a LAI reduced the risk of relapse by $20 \%$ and $50 \%$, as compared to the same AP given by oral route and belonging to the first and the second generation, respectively. Furthermore, in the real-world setting the effectiveness significantly increases with decreasing administration frequency, with a relative reduction in the risk of relapse equal to $10 \%$ for each additional week of inter-dose interval. Taking into account generation, route and frequency of administration our results show that, taking FGA OAP as reference, the relapse rate decreased with lower administration frequency, with SGA LAI administered once every 90 days which is associated with the greatest reduction in the risk of relapse (-84\%). As shown in Table III, only one RCT that compares 90-day LAI was included in the meta-analysis [48]. This trial involved 1016 patients who were randomly assigned to 90-day paliperidone or 30-day paliperidone and showed noninferiority of the 3-month formulation in terms of relapse rate. The results demonstrated the noninferiority of the 3-monthly administration in terms of relapse rate and the mITT analysis showed that the nominal hazard ratio for a patients switching from 90 -day $(n=483)$ to 30 -day $(n=512)$ formulation was 0.87 (95\% CI: 0.56-1.34).

When the results of the meta-analysis are used to feed an economic evaluation, in order to estimate the management cost of an episode of relapse, the results show that the SGA administered every 90 days is the strategy with the least expected cumulative cost at 1 and 5 years (€ 3,795 and $€ 21,270$, respectively).

Observing the composition of the single cost items (relapse management and drug cost) it can be seen that the cost for relapse management decreases moving from the daily administration to less frequent administration schedules. Furthermore, even if the component related to the drug acquisition becomes more prevalent moving from the least to the most effective treatment, the clinical advantage in terms of relapse prevention compensates the drug cost, resulting in a lower total expenditure.

Our conclusions are in line with a recent systematic review, which aimed to investigate the economic impact of schizophrenia on the healthcare system in Europe and to identify the most important cost driver in the management of schizophrenia [51]. According to Kovacs et al. the component related to the hospital stay represents the major direct cost of schizophrenia, accounting for $27 \%$ to $92 \%$ of total direct medical costs, depending on the country considered. Among the suggestions given by the Authors in order to reduce the economic burden associated with schizophrenia and to improve the allocation of financial resources, there are the reduction of the number of hospitalizations and the improvement of persistence and adherence in antipsychotic therapy [51].

At the light of these results, it can be said that more efforts are needed in order to improve the management of patients with schizophrenia and to enhance identification of patients who can benefit most from the treatment with LAIs achieving better clinical and economic outcomes.

The main limitation of our study is the inclusion in the meta-analysis of only one trial that compares 90-day vs. 30-day administration, however, due to the structure of the model, comparing strategies with differing administration frequency, provide information about the effect of the extension of the administration interval. 


\section{CONCLUSION}

Since one of the major goal of the treatment of schizophrenia is to prevent/delay relapse, at the light of our results SGA LAIs administered every 90 days seems to be the best option from both the clinical and economic perspectives.

\section{Acknowledgements}

We would like to thank the advisory board members for their expert opinions:

- Luca Degli Esposti, CliCon S.r.l. - Health Economics \& Outcome Research, Bologna

- Roberta Di Turi, Direttore Farmacia Ospedaliera Presidio Ospedaliero Giovan Battista Grassi, Roma

- Giuseppe Ducci, Direttore del Dipartimento di Salute Mentale U.O.C. Prevenzione Interventi Precoci Salute Mentale U.O.C. S.P.D.C. S. Filippo Neri, Roma

- Edvige Facchi, Direttore UFSAM Grosseto. AUSL Toscana SudEst

- Andrea Fagiolini, Professore di Psichiatria dell'Università di Siena

- Antonio Lora, Direttore Dipartimento Salute mentale, ASST Lecco

- Claudio Mencacci, Direttore Dipartimento Neuroscienze e Salute mentale P.O. Fatebenefratelli e Oftalmico, Milano

- Marzia Mensurati, Responsabile Farmacia Territoriale ASL Roma 5

- Gaetana Muserra, Direttore S.C. Farmacia P.O. Fatebenefratelli e Oftalmico, Milano

- Giuseppe Nicolò, Direttore Dipartimento di Salute Mentale ASL Roma 5

- Mauro Percudani, Direttore Dipartimento di Salute Mentale e delle Dipendenze, ASST Grande Ospedale Metropolitano Niguarda, Milano

- Paolo Rossi Prodi, Direttore della UO Salute Mentale. AUSL Toscana Centro

\section{Funding}

The study was made possible by an unconditional grant from Janssen-Cilag SpA.

\section{Conflict of interest}

OZ, GG, and MP are employees of Adres, which has received project funding by Janssen-Cilag SpA for the conduct of the study.

LP is co-owner and employee of Adres, which has received project funding by Janssen-Cilag SpA for the conduct of the study. LP is an editorial member of Farmeconomia. Health Economics and Therapeutic Pathways

\section{REFERENCES}

1. Olivares JM, Sermon J, Hemels M, et al. Definitions and drivers of relapse in patients with schizophrenia: a systematic literature review. Ann Gen Psychiatry 2013; 12: 32; https://doi.org/10.1186/1744-859X-12-32

2. Fagiolini A. Il ruolo dei LAI nel percorso del paziente. Journal of Psychopathology 2015; 21(Suppl): 13-5

3. Spina E, Canonico PL, de Bartolomeis A. Antipsicotici iniettabili a lunga durata d'azione nel trattamento della schizofrenia. Società Italiana di Farmacologia. Position Paper, 2015

4. Kane JM. Treatment strategies to prevent relapse and encourage remission. J Clin Psychiatry 2007; 68 Suppl 14: 27-30

5. Kane JM. Improving patient outcomes in schizophrenia: achieving remission, preventing relapse, and measuring success. J Clin Psychiatry 2013; 74: e18; https://doi.org/10.4088/JCP.12117tx1c

6. Miyamoto S, Wolfgang Fleischhacker W. The Use of Long-Acting Injectable Antipsychotics in Schizophrenia. Curr Treat Options Psychiatry 2017; 4: 117-26; https://doi.org/10.1007/s40501-017-0115-z

7. Correll CU, Citrome L, Haddad PM, et al. The Use of Long-Acting Injectable Antipsychotics in Schizophrenia: Evaluating the Evidence. J Clin Psychiatry 2016; 77: 1-24; https://doi.org/10.4088/JCP.15032su1

8. Kane JM, Garcia-Ribera C. Clinical guideline recommendations for antipsychotic long-acting injections. $\mathrm{Br} J$ Psychiatry Suppl 2009; 52: S63-7; https://doi.org/10.1192/bjp.195.52.s63

9. Kishimoto T, Nitta M, Borenstein M, et al. Long-acting injectable versus oral antipsychotics in schizophrenia: a systematic review and meta-analysis of mirror-image studies. J Clin Psychiatry 2013; 74: 957-65; https://doi. org/10.4088/JCP.13r08440

10. Kishimoto $\mathrm{T}$, Robenzadeh $\mathrm{A}$, Leucht $\mathrm{C}$, et al. Long-acting injectable vs oral antipsychotics for relapse prevention in schizophrenia: a meta-analysis of randomized trials. Schizophr Bull 2014; 40: 192-213; https:/doi.org/10.1093/ schbul/sbs 150 
11. Moher D, Liberati A, Tetzlaff J, et al.; PRISMA Group. Preferred reporting items for systematic reviews and meta-analyses: the PRISMA statement. J Clin Epidemiol 2009; 62: 1006-12; https://doi.org/10.1016/j.jclinepi.2009.06.005

12. IQVIA S.p.A - data on file

13. Informatore Farmaceutico on-line. Available at: http://www.codifa.it/ (last accessed June 2018)

14. Pilon D, Joshi K, Tandon N, et al. Treatment patterns in Medicaid patients with schizophrenia initiated on a first- or second-generation long-acting injectable versus oral antipsychotic. Patient Preference and Adherence 2017; 11: 619-29

15. Ascher-Svanum H, Zhu B, Faries DE, et al. The cost of relapse and the predictors of relapse in the treatment of schizophrenia. BMC Psychiatry 2010; 10: 2; https://doi.org/10.1186/1471$244 \mathrm{X}-10-2$

16. Rahmati M, Rahgozar M, Fadaei F, et al. Identifying Some Risk Factors of Time to Relapses in Schizophrenic Patients using Bayesian Approach with Event-Dependent Frailty Model. Iran J Psychiatry 2015; 10: 123-7

17. Baser O, Xie L, Pesa J, et al. Healthcare utilization and costs of Veterans Health Administration patients with schizophrenia treated with paliperidone palmitate long-acting injection or oral atypical antipsychotics. J Med Econ 2015; 18: 357-65; https://doi.org/10.3111/13 696998.2014.1001514

18. Bitter I, Katona L, Zámbori J, et al. Comparative effectiveness of depot and oral second generation antipsychotic drugs in schizophrenia: a nationwide study in Hungary. Eur Neuropsychopharmacol 2013; 23: 1383-90; https://doi.org/10.1016/j.euroneuro.2013.02.003

19. Grimaldi-Bensouda L, Rouillon F, Astruc B, et al.; CGS Study Group. Does long-acting injectable risperidone make a difference to the real-life treatment of schizophrenia? Results of the Cohort for the General study of Schizophrenia (CGS). Schizophr Res 2012; 134: 187-94; https://doi.org/10.1016/j.schres.2011.10.022

20. Guo X, Fang M, Zhai J, et al. Effectiveness of maintenance treatments with atypical and typical antipsychotics in stable schizophrenia with early stage: 1-year naturalistic study. Psychopharmacology (Berl) 2011; 216: 475-84; https://doi.org/10.1007/s00213-011-2242-3

21. Joshi K, Pan X, Wang R, et al. Healthcare resource utilization of second-generation longacting injectable antipsychotics in schizophrenia: risperidone versus paliperidone palmitate. Curr Med Res Opin 2016; 32: 1873-81

22. Lafeuille MH, Grittner AM, Fortier J, et al. Comparison of rehospitalization rates and associated costs among patients with schizophrenia receiving paliperidone palmitate or oral antipsychotics. Am J Health Syst Pharm 2015; 72: 378-89; https://doi.org/10.2146/ ajhp140219

23. Marcus SC, Zummo J, Pettit AR, et al. Antipsychotic Adherence and Rehospitalization in Schizophrenia Patients Receiving Oral Versus Long-Acting Injectable Antipsychotics Following Hospital Discharge. J Manag Care Spec Pharm 2015; 21: 754-68

24. Morrato EH, Parks J, Campagna EJ, et al. Comparative effectiveness of injectable paliperidone palmitate versus oral atypical antipsychotics: early postmarketing evidence. J Comp Eff Res 2015; 4: 89-99; https://doi.org/10.2217/cer.14.50

25. Ren XS, Crivera C, Sikirica M, et al. Evaluation of health services use following the initiation of risperidone long-acting therapy among schizophrenia patients in the veterans health administration. J Clin Pharm Ther 2011; 36: 383-9; https://doi.org/10.1111/j.13652710.2010.01211.x

26. Schreiner A, Svensson A, Wapenaar R, et al. Long-acting injectable risperidone and oral antipsychotics in patients with schizophrenia: results from a prospective, 1-year, noninterventional study (InORS). World J Biol Psychiatry 2014; 15: 534-45; https://doi.org/1 $0.3109 / 15622975.2014 .902990$

27. Tiihonen J, Haukka J, Taylor M, et al. A nationwide cohort study of oral and depot antipsychotics after first hospitalization for schizophrenia. Am J Psychiatry 2011; 168: 603-9; https://doi.org/10.1176/appi.ajp.2011.10081224 
28. Tiihonen J, Mittendorfer-Rutz E, Majak M, et al. Real-World Effectiveness of Antipsychotic Treatments in a Nationwide Cohort of 29823 Patients With Schizophrenia. JAMA Psychiatry 2017; 74: 686-93; https://doi.org/10.1001/jamapsychiatry.2017.1322

29. Tiihonen J, Wahlbeck K, Lönnqvist J, et al. Effectiveness of antipsychotic treatments in a nationwide cohort of patients in community care after first hospitalisation due to schizophrenia and schizoaffective disorder: observational follow-up study. BMJ 2006; 333: 224

30. Voss EA, Ryan PB, Stang PE, et al. Switching from risperidone long-acting injectable to paliperidone long-acting injectable or oral antipsychotics: analysis of a Medicaid claims database. Int Clin Psychopharmacol 2015; 30: 151-7; https://doi.org/10.1097/ YIC.0000000000000068

31. Alphs L, Benson C, Cheshire-Kinney K, et al. Real-world outcomes of paliperidone palmitate compared to daily oral antipsychotic therapy in schizophrenia: a randomized, open-label, review board-blinded 15-month study. J Clin Psychiatry 2015; 76: 554-61; https://doi. org/10.4088/JCP.14m09584

32. Buckley PF, Schooler NR, Goff DC, et al.; PROACTIVE Study. Comparison of SGA oral medications and a long-acting injectable SGA: the PROACTIVE study. Schizophr Bull 2015; 41: 449-59; https://doi.org/10.1093/schbul/sbu067

33. Carpenter WT Jr, Buchanan RW, Kirkpatrick B, et al. Comparative effectiveness of fluphenazine decanoate injections every 2 weeks versus every 6 weeks. Am J Psychiatry 1999; 156: $412-8$

34. Csernansky JG, Mahmoud R, Brenner R; Risperidone-USA-79 Study Group. A comparison of risperidone and haloperidol for the prevention of relapse in patients with schizophrenia. N Engl J Med 2002; 346: 16-22; https://doi.org/10.1056/NEJMoa002028

35. Detke HC, Weiden PJ, Llorca PM, et al. Comparison of olanzapine long-acting injection and oral olanzapine: a 2-year, randomized, open-label study in outpatients with schizophrenia. $J$ Clin Psychopharmacol 2014; 34: 426-34; https://doi.org/10.1097/JCP.0000000000000140

36. Fleischhacker WW, Sanchez R, Perry PP, et al. Aripiprazole once-monthly for treatment of schizophrenia: double-blind, randomised, non-inferiority study. Br J Psychiatry 2014; 205: 135-44; https://doi.org/10.1192/bjp.bp.113.134213

37. Glick ID, Berg PH. Time to study discontinuation, relapse, and compliance with atypical or conventional antipsychotics in schizophrenia and related disorders. Int Clin Psychopharmacol 2002; 17: 65-8; https://doi.org/10.1097/00004850-200203000-00004

38. Hogarty GE, Schooler NR, Ulrich R, et al. Fluphenazine and social therapy in the aftercare of schizophrenic patients. Relapse analyses of a two-year controlled study of fluphenazine decanoate and fluphenazine hydrochloride. Arch Gen Psychiatry 1979; 36: 1283-94; https:// doi.org/10.1001/archpsyc.1979.01780120013001

39. Ishigooka J, Nakamura J, Fujii Y, et al.; ALPHA Study Group. Efficacy and safety of aripiprazole once-monthly in Asian patients with schizophrenia: a multicenter, randomized, double-blind, non-inferiority study versus oral aripiprazole. Schizophr Res 2015; 161: 421-8; https://doi.org/10.1016/j.schres.2014.12.013

40. Kane JM, Detke HC, Naber D, et al. Olanzapine long-acting injection: a 24-week, randomized, double-blind trial of maintenance treatment in patients with schizophrenia. $\mathrm{Am} J$ Psychiatry 2010; 167: 181-9; https://doi.org/10.1176/appi.ajp.2009.07081221

41. Kane JM, Osuntokun O, Kryzhanovskaya LA, et al. A 28-week, randomized, double-blind study of olanzapine versus aripiprazole in the treatment of schizophrenia. J Clin Psychiatry 2009; 70: 572-81; https://doi.org/10.4088/JCP.08m04421

42. Keks NA, Ingham M, Khan A, et al. Long-acting injectable risperidone v. olanzapine tablets for schizophrenia or schizoaffective disorder. Randomised, controlled, open-label study. $\mathrm{Br}$ J Psychiatry 2007; 191: 131-9; https://doi.org/10.1192/bjp.bp.105.017020

43. Kim B, Lee SH, Choi TK, et al. Effectiveness of risperidone long-acting injection in firstepisode schizophrenia: in naturalistic setting. Prog Neuropsychopharmacol Biol Psychiatry 2008; 32: 1231-5; https://doi.org/10.1016/j.pnpbp.2008.03.012 
44. Lieberman JA, Stroup TS, McEvoy JP, et al.; Clinical Antipsychotic Trials of Intervention Effectiveness (CATIE) Investigators. Effectiveness of antipsychotic drugs in patients with chronic schizophrenia. N Engl J Med 2005; 353: 1209-23; https://doi.org/10.1056/ NEJMoa051688

45. Malla A, Chue P, Jordan G, et al. An Exploratory, Open-Label, Randomized Trial Comparing Risperidone Long-Acting Injectable with Oral Antipsychotic Medication in the Treatment of Early Psychosis. Clin Schizophr Relat Psychoses 2016; 9: 198-208; https:// doi.org/10.3371/CSRP.MACH.061213

46. McEvoy JP, Byerly M, Hamer RM, et al. Effectiveness of paliperidone palmitate vs haloperidol decanoate for maintenance treatment of schizophrenia: a randomized clinical trial. JAMA 2014; 311: 1978-87; https://doi.org/10.1001/jama.2014.4310

47. Rosenheck RA, Krystal JH, Lew R,et al.; CSP555 Research Group. Long-acting risperidone and oral antipsychotics in unstable schizophrenia. N Engl J Med 2011; 364: 842-51; https:// doi.org/10.1056/NEJMoa1005987

48. Savitz AJ, Xu H, Gopal S, et al. Efficacy and Safety of Paliperidone Palmitate 3-Month Formulation for Patients with Schizophrenia: A Randomized, Multicenter, Double-Blind, Noninferiority Study. Int J Neuropsychopharmacol 2016; 19; https://doi.org/10.1093/ijnp/ pyw018

49. Schooler N, Rabinowitz J, Davidson M, et al.; Early Psychosis Global Working Group. Risperidone and haloperidol in first-episode psychosis: a long-term randomized trial. Am J Psychiatry 2005; 162: 947-53; https://doi.org/10.1176/appi.ajp.162.5.947

50. Schooler NR, Levine J, Severe JB, et al. Prevention of relapse in schizophrenia. An evaluation of fluphenazine decanoate. Arch Gen Psychiatry 1980; 37: 16-24; https://doi. org/10.1001/archpsyc.1980.01780140018002

51. Kovács G, Almási T, Millier A, et al. Direct healthcare cost of schizophrenia - European overview. Eur Psychiatry 2018; 48: 79-92; https://doi.org/10.1016/j.eurpsy.2017.10.008 